\title{
On the Standardization of Lethal Injections in China
}

\author{
Bing Zou ${ }^{1}$ \\ ${ }^{1}$ School of Law, Southwest University, Chongqing, China \\ Correspondence: Bing Zou, School of Law, Southwest University, Chongqing 400715, China. E-mail: \\ Zblaw99@163.com
}

Received: February 21, 2012

Accepted: March 11, 2012 Published: May 1, 2012

doi:10.5539/ass.v8n6p82

URL: http://dx.doi.org/10.5539/ass.v8n6p82

\begin{abstract}
Lethal injections have been increasingly employed in China nowadays. Due to the lack of specific institutions in China's legislation, there is no universal and definite standard for the options and execution procedure of lethal injections, causing lots of problems. Therefore, an option for lethal injections should be established and relevant execution procedure should be further improved as well.
\end{abstract}

Keywords: lethal injections, standard, option, execution procedure

\section{The History of Lethal Injections}

Lethal injection was initially proposed in New York in 1888 although it gave way to electrocution there finally. It was not until 1977 that the first draft of law on lethal injections was produced in Oklahoma of the United States. In May $11^{\text {th }}$, this state became the first place all over the world employing lethal injections legally while the first person to receive this new way of execution died in Texas in 1982. Not until July $21^{\text {st }} 2009$ did Keane, an amok from Ohio, became the $1000^{\text {th }}$ criminal receiving lethal injection since the recovery of death penalty in 1976 .

In China, Yunnan Province was the first to fully implement lethal injections. In May 1999, Kunming Intermediate People's Court launched a pilot project of this new way of execution. In January 1997, it was laid down that death penalty can be conducted in the way of shooting or injection in Article 212 of the amended Criminal Law, which, for the first time, confirmed the legality of lethal injections in China. On March $28^{\text {th }} 1997$, the first case of lethal injection was conducted by Kunming Intermediate People's Court. In November $4^{\text {th }}$, another case went public. It was in September 2001 that a conference on the adoption of lethal injections by the courts all over China was held by the Supreme People's Court in Kunming, at which Regulations on the Implementation of Lethal Injections (trial) was issued, followed by A Notice on the Implementation of Lethal injections and Execution Rules for Judicial Police in People's Courts. On February 27 $7^{\text {th }}$ 2003, a conference on lethal injections was held in Yuxi by Yunnan People's Court to fully promote the implementation of lethal injections in the whole province.

\section{The Current Situation of Lethal Injections}

\subsection{Nations and Areas Adopting Lethal Injections}

Up to now, only the United States, Singapore, Thailand and China have conducted lethal injections, along with Guatemala, the Philippines and Taiwan of China which permit lethal injections.

Among all the 38 states with death penalty in the United States, 34 states take lethal injections as the first choice for death penalty. It is also adopted in the American Army. Statistics show that 59 criminals were executed in the United States in 2004, 58 among which received lethal injections. The number of states who were authorized to conduct lethal injections was increased from 27 in 1994 to 37 in 2004.

In the United States, even in those states which have adopted lethal injections in their legislation some improvements have been made constantly to adjust to increasingly complex situations, such as California, Florida, Kentucky, Ohio, South Dakota, North Carolina, Tennessee, Maryland and so on which have made several amendments to the criteria for the application of lethal injections to actively deal with new problems. Ever since 1982, 80\% of the criminals who have been sentenced to death have been killed with lethal injections. Guatemala witnessed its first lethal injection on February $10^{\text {th }} 1998$. The Philippines' first lethal injection occurred in February 1999, which was also the first death penalty since 1976. Thailand became another nation adopting injection as the main way of death penalty in October 2003.

In China, after the issuance of new criminal law in 1997, the Supreme People's Court began to choose some trial spots for intermediate people's courts in different areas. Currently, lots of cities have adopted lethal injections 
including Kunming, Changsha, Chengdu, Beijing, Shenzhen, Shanghai, Guangzhou, Nanjing, Chongqing, Hangzhou, Dalian, Anshan, Pingdingshan, Jiaozuo, Wuhan, Heilongjiang, Urumqi and so on.

It was in 2002 that Shanghai claimed that shooting would give way to injection when conducting death penalty. At present, shooting has been completely abolished in Yunnan, Zhejiang, Chengdu and Taiyuan along with some other cities which are planning on a full implementation of lethal injections as well.

It was mentioned at the National Forum on Criminal Judgment closed on June 142009 that lethal injections would be gradually adopted in Beijing and be fully implemented by the end of 2010. Meanwhile, the execution room for lethal injection near Beijing No.1 Prison will be fully operational before the end of the year. However, there has been no full implementation of this plan up to now.

On December $9^{\text {th }} 2009$, it was announced by the Supreme People's Court of Liaoning Province that it will be the first province in China to permit no other way for death penalty, which marked the complete abolishment of shooting there.

\subsection{Some Problems Related to Lethal Injections}

\subsubsection{A Lack of Clear Standards for an Option for Lethal Injections}

In China, it is laid down in law that shooting or injection can be used for death penalty, leaving it unclear whether a criminal has the qualification and the right to choose how to end their life. From the legislative perspective, injection should be encouraged when executing death penalty or it can be literally understood that criminals should have the right to choose their preferable way. In judicial practice, however, this option goes to the court without any legal evidence. It is decided by the court to whom shooting or injection is employed. Currently there is no rule saying that it is up to the executive bureau to choose the way of death penalty. According to the legal theory that national authorities cannot conduct unauthorized behaviors, it is a violation against China's law and legal theory to deprive criminals of their options.

Due to the imbalance in economic development, there is no universal opinion and law-execution way by local courts. Some areas have no financial capacity to afford a series of expenses for lethal injections while some try to avoid disputes and troubles by adopting shooting as the only way for death penalty. With the options in the hand of the court and no universal standards during the execution process, such unlimited discretion may lead to some unfair cases of death penalty. Because of different paces in the transition of criminal opinions, it is a luxury for some ordinary criminals to have lethal injections in many areas. On the premise that the options falls into the hand of the court, is lethal injection associated with the status of criminals? For the lethal injection of Liu Yong who used to be a notorious gang leader, Liaoning Supreme People's Court spent over 400,000 yuan on a special vehicle for lethal injections. Is it an improper exploitation of discretion by the court? Is it a privilege for ranking officials to receive lethal injections or is it a kind of welfare in the case of death penalty?

Supposing it is originally intended to endow criminals with options for their preferable way for death penalty, this is a significant step on the way towards the abolishment of death penalty. However, since lethal injection is restricted by many factors such as finance, technology, staff, regional development, people's opinions, politics and so on, it is of less feasibility to give options to criminals unconditionally. It may have a strong impact on people's traditional opinions on criminal punishment as well as increase judicial cost and therefore heavy financial burdens. As a result, even when criminals have their options, lethal injections can only be limited to a certain range in accordance with the reality and be guaranteed by a fixed standard. Along with economic development and technological advance, the cost for lethal injections will be cut down, hence spreading this new way to a wider field and finally realizing equality and justice in criminals' options.

\subsubsection{No Clear Standard for the Execution Procedure}

In those nations adopting lethal injection, a lengthy process or failure has occurred due to imperfect execution process or a lack of standards. When a criminal named Newton received lethal injection in US in 2007, it took 16 minutes to die after the injection during which the executive staff went through at least 10 failures in finding his vein $(\mathrm{Li}, 2010)$. At the same time, due to the effect of drugs, the criminal vomited, had a trembling and twisted underjaw and even had two strokes of convulsion. In another case, when the judicial staff in Ohio executed death penalty on Rommel Bloom, this lethal injection had to be postponed due to the failure of finding his vein in 2 hours. The big problem in the procedure of execution raised a question whether it is inhuman to conduct death penalty on the same criminal repeatedly and whether it is permitted to have another one after a failure in lethal injection. Due to a lack of relevant standards, during the execution in US, there have been many cases in which insufficient drugs were used in injection or the employed drugs were not in conformity with the criminal's constitution.

In China, a severe problem also occurred during the second operation with a high-speed execution pump conducted by Hangzhou Intermediate People's Court. Since the remains of Drug 1 got coagulated with Drug 2 when they were mixed, the injection pipe was choked. Then when Drug 2 was continuously pushed forward in 
the pipe, the pipe exploded eventually (He, 2008). To sum up, there are following problems in China's lethal injection practice: first, there is no standard for the qualification of the execution staff. There is no definite standard to define whether judicial police, judicial doctors, medical professionals or other professional persons should be responsible for the execution process. Second, there is no enough executive staff for lethal injections. In addition, it remains unclear how to train unprofessional staff, how to establish the execution staff's psychological interference system and the degree of effect on the execution staff's physical health. From the perspective of the object of lethal injections, there is also no standard on the length of the whole injection process, the location for execution, the adaptability of criminals to the injected drugs, whether a manual way or an injection pump should be employed, what drugs, what order or dosage should be adopted to be in better conformity with criminals' constitution and to lessen or at lest not to increase their pains. Finally, there is no standard on the recording of execution reports and the monitoring of the execution process.

\section{The Improvement in the Execution Standards}

\subsection{Perfecting the Options for Lethal Injections}

On whether a criminal should be given the right to choose the preferable way of death penalty, there is no definition in China's Criminal Law issued in 1996, only putting it down that shooting and injection can be employed to execute death penalty. It is initially intended to encourage lethal injections if conditions permit due to the following reasons: first, such an option reflects the principle of fairness. Everyone is equal before the law with no exception for the criminals sentenced to death. Regardless of their status, identity and economic conditions, they should be given an option once they are sentenced to death. Second, the option will not lessen the deterrent of criminal punishment. With the increasingly extensive spread of humanism and the concept of human rights, people are more concerned about their rights to life than fearful about the way to execute death penalty to some extent. Therefore, it is unwise to increase the deterrent by making criminal punishment inhuman. Third, it is unreasonable to deny the options for criminals. In China's judicial practice, the options for criminals have been transformed into the discretion of the court, which is a violation against laws and regulations. It is improper to deny criminals' options without any relevant stipulation.

Certainly, due to great differences lying in different parts of China, an absolutely universal standard cannot be adopted in the current judicial practice. It can be listed in law in what situations criminals should be given an option: for those old or female criminals with less subjective evil character; for those criminals who are willing to donate their organs to atone for their crimes; for disable criminals or those having AIDS, other infectious diseases or some other severe diseases (2006); or those criminals with light plots or some plots rendering meritorious services; for the criminals committing non-violent economic crimes; for impulsive criminals under special circumstances; for other situations in which an option should be offered to criminals.

\subsection{Perfecting the Standards for the Execution Procedure}

\subsubsection{Current Injection Procedure in China}

There are two main lethal injection ways in China now: one is conducted in a vehicle and the other is in a fixed place of execution. In Beijing, for example, there is a two-story building as its fixed place of execution. On the first floor there is an execution room, a torture room, a mortuary, an observation room and so on equipped with injection pumps and disinfecting apparatuses. On the second floor is the office area. Iron fences are installed inside every window. Although the exterior wall is not high, some infrared monitoring appliances with complex shapes are installed. Meanwhile, a big screen is also installed to monitor the whole execution process.

At the first step of the lethal injection process, a criminal is fixed on the bed by judicial police and the needle head is put into the vein of the criminal. Once the order is given, the executive person will press the injection button to inject the drugs into the vein of the criminal. Finally, a judicial doctor will announce the death of the criminal according to his heartbeat and breath. The whole injection process will last less than 2 minutes with light music in the background. The drugs are composed of 4 doses with the same color among which only one is deadly. This is the same as that in US.

Finally, relevant data on the lethal injection process will be collected.

\subsubsection{The Whole Process of Lethal Injection in the United States}

The transition of location before the execution: after the issuance of the writ of execution by the court and the establishment of the execution date, the criminal will be transferred from an ordinary prison to the prison near the execution place or to another central prison.

24 hours before the execution: family members, friends, lawyers and priests coming to hear confessions are permitted to see the criminal in the guarding area or a special visiting room.

Several hours before the execution: the criminal's demand should be fulfilled to the largest extent and he will have his last dinner. Then, the warden and a priest will come to stay with the criminal until the end of the 
execution along with some witnesses who are expected to come 20 minutes to 2 hours prior to the execution. At this moment, the criminal is dressed properly, waiting for the signal with the priest. When the warden sent the signal, the criminal will be attached to EKG. At the same time, the executive group stays in the lobby near the execution room, where drugs and a telephone which is used to contact with the national officials who have the right to postpone the execution are placed. If no call comes before the execution, the executive staff will insert the venous duct into the criminal's arm, in which normal saline is flowing. Then with the curtains drawn up, if it is in a room with a single-face mirror, only the witnesses can see the criminal while in a room with transparent glass, they can see each other. The criminal has the chance to leave the last written or oral announcement which will be recorded and publicized.

How to kill the criminal with drugs: the execution can be done by automatic machines or manual injection. For the sake of safety, some executive staff, composed of prison staff, may wear a helmet. The same group or different persons in turn stay in a separate room (lobby) or hide behind the curtains. With the signal sent, they will begin the injection. Different drugs may be injected by several persons at the same time, among which only one is deadly. The order to use the drugs is as follows(1) Anaesthetic is injected, a kind of barbituric acid called Sodium thiopental or Pen-tothal, to make the criminal asleep. Then the venous duct will be washed with normal saline. (2) Muscle relaxation reagent is injected, called Pancuronium bromide or Pavulon to paralyze diaphragm and lungs, hence stopping the criminal's breath. Pancuronium Bromide, Tubo-curarine Chloride and Succinylcholinechloride can also be employed. Then normal saline will be used again for washing the venous duct. (3) A poisonous drug, potassium chloride, is injected to stop the electric signal of the system related to the heart and therefore to stop the heartbeat of the criminal.

\subsection{Countermeasures}

First comes the lack of standards for the qualification of the executive subject. Injection trainings on judicial police and doctors should be strengthened, hence avoiding employing medical professionals and other persons and lessening their conflicts with doctors' professional ethics. As for the employed drugs, potassium chloride has extremely strong volatility, severely affecting the physical health of the executive staff. Therefore, an alternative drug should be developed.

Second is the insufficient size of the executive group. The number of the executive staff should be increased and professional trainings on injection especially on the verification of tetrodonine to avoid apparent death during the execution process should be provided. In addition, a system of psychological interference for the executive staff should be perfected, in which psychology will be made use of to conduct psychological and professional trainings. To be specific, three or more persons are asked to press the injection button at the same time so as to leave it unknown who has really pressed the button.

Third, the dosage and order of using drugs can be borrowed from that in the United States. Meanwhile, in the aspect of the execution way, the manual way is better since some break-downs caused by machines may be difficult to solve. Compared with an execution vehicle which requires regular maintenance, an execution room is more endurable. As for those criminals with diabetes, dark-colored skin, overweight figure, overdeveloped muscles, extreme sensitivity or using drugs, the injection way is not encouraged for their execution.

Finally is about the lack of standards for the recording of execution reports and the supervision of the execution process. A series of procedures in the execution process should be recorded in detail to accumulate data and have comparative analysis later. In addition, the current supervision system should be changed. Instead of being distributed by the Supreme People's Court, drugs should be managed by the supreme courts at the provincial level, hence reducing the transport cost for delivering drugs. Besides, a universal standard should be established with some preferential financial policies for those poor areas to help them establish execution rooms. A preparation system for emergencies should also be established and perfected.

\section{References}

(2006). So Long as They Die: Lethal Injections in the United States. Human Rights Watch, 18(1).

Deng, Tianjiang. (2004). The Development of Protection of Humanright.Chinese Lawyer, 6.

Guan, Jindong. (2001). Lethal Injections have been Used Widely in China. People Court, 9.

He, Chengbing, \& Li, Jiaxian. (2008). Three Painful Topics on Lethal Injections. Research on Rules of Law, 10.

Li, Kun. (2010). The Revelations of the Disputes on Lethal Injections in US on China. Social Scientist, 5.

Wang, Wenjun, Xu, Maochao, \& Hu, Zhongguo. (2009). On the Development of Lethal Injections in China. Looking Truth, 1 .

Zhao, Li. (2010). On the Lethal Injections of China. Journal of Ankang University, 22. 